\title{
Possible role for green tea in ovarian cancer prevention
}

\section{AndyH Le, MidhdleL Frase \& Colin W Binns}

${ }^{\dagger}$ Author for correspondence Curtin University of Technology, School of Public Health, GPO Box U 1987, Perth, WA 6845, Australia Tel.: +61 892664 180; Fax: +61 892662 958; Andy.Lee@curtin.edu.au

Keywords: biologic mechanisms, catechins, epidemiologic studies, green tea, ovarian cancer, polyphenols

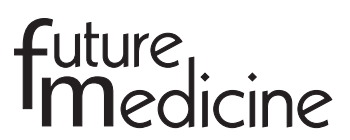

\author{
Ovarian cancer is the leading cause of death from gynecologic cancer. Tea, especially \\ green tea, has shown promise in the prevention of several cancers. Green tea contains a \\ number of compounds, including polyphenols, that have chemopreventive properties. \\ There is much evidence from in vitro and animal studies suggesting that components of tea \\ are associated with decreased risk or progression of ovarian cancer. However, \\ epidemiologic studies have generated inconsistent results. Recent research conducted in \\ China reported reduced risk of ovarian cancer and increased survival post diagnosis with \\ green tea consumption. This review presents emerging evidence and the authors' \\ perspectives on the role of green tea in ovarian cancer prevention.
}

0 varian cancer is the leading cause of death from gynecologic cancer [1]. It has a high fatality:case ratio because it commonly remains undetected until the advanced stages [2] and has a tendency to recur [1]. Moreover, relatively little is known about its etiology and no effective screening programs are available [2]. The incidence of ovarian cancer varies considerably between geographic areas, with most Asian countries having approximately a quarter of the incidence of northern European countries [2]. This suggests that lifestyle and dietary factors may influence the risk and progression of ovarian cancer [3].

Tea, especially green tea, has shown promise in the prevention of several cancers. It contains a number of compounds, including polyphenols, that have chemopreventive properties. Although there is ample evidence from in vitro and animal studies indicating that components of tea are associated with decreased risk or progression of several cancers [4], relatively few studies have specifically investigated ovarian cancer.

Epidemiologic studies on tea and ovarian cancer have generated inconsistent results. H owever, recent research reported a protective effect of green tea on ovarian cancer risk [5] and survival rates [6] among Chinese women. Currently, epidemiologic evidence is strongest for organs of the gastrointestinal tract, possibly because of their direct contact with tea constituents [7-10]. Evidence has also emerged from human observational studies on cancer of the skin [11], prostate [12], breast [13-15], pancreas, esophagus and lung [16], and from over 80 published studies in animal models [4]. Interestingly, the majority of studies reporting protective effects were conducted in Asian countries where green tea is predominantly consumed.
The in vitro and animal model evidence for the protective effect of green tea on ovarian cancer, as well as results from epidemiologic studies, are the focus of this review. Articles were located by searching the PubM ed, CINAHL and ProQ uest databases using the keywords 'tea' and 'ovarian cancer' without any restriction on publication date. The corresponding reference lists were also searched for relevant articles.

Tea components \& types

Tea is one of the most popular beverages worldwide, consumed second only to water [17]. Of the total tea produced and consumed, $78 \%$ is black, $20 \%$ green and less than $2 \%$ oolong [17]. Black tea is primarily consumed in Western countries while green tea is mainly consumed in China, Japan, India and a few countries in N orth Africa and the M iddle East [17]. Tea contains a number of compounds such as polyphenols that can protect against cancer. M ost evidence comes from catechins, a category of polyphenols in green tea including (-)-epicatechin, (-)-epicatechin-3-gallate, (-)-epigallocatechin and (-)epigallocatechin3-gallate [18]. Epicatechin-3-gallate (EGCG) is the major component, accounting for $40 \%$ of the total polyphenol content in green tea extract. It is considered to be the most abundant and active constituent [18]. Tea al so contains caffeine, which has been shown to have anticarcinogenic effects in some animal studies [19-22].

While different types of tea are originally derived from the same plant, Camellia sinensis, they undergo different manufacturing processes, changing the profile of compounds [18]. Green tea leaves are steamed when harvested to prevent fermentation, oolong tea is partially fermented, whereas black tea leaves are allowed to wither 
and are rolled and crushed, initiating fermentation of polyphenols [18]. This process results in oxidation of simple polyphenols to complex compounds such as theaflavins and thearubigins, and reduces the catechin content of black tea to approximately a third of that in green tea [18]. Therefore, consumption of different types of tea may have varying effects on cancer prevention.

\section{In vitro \& animal studies on green tea \& cancer}

The strongest evidence linking tea to cancer prevention emerged from in vitro cell cultures and animal model studies [4]. M any experimental studies have examined the effect of green tea extract or tea components on cancer, with a focus on the catechin EGCG. The majority of these studies have shown a protective effect at one or more of the multiple stages of tumorigenesis (initiation, promotion or progression) [4].

The protective effects of tea components have been demonstrated at a number of organ sites including the gastrointestinal tract, oral cavity, lung, esophagus, skin, liver, pancreas, bladder, mammary gland and prostate $[4,23]$. Although potential mechanisms have been proposed to explain the cancer preventive activity, they are not firmly established in animals or humans [4]. G reen tea components can be distributed to a wide variety of target organs in rodents after ingestion, including the ovary [24]. Plausible biologic mechanisms of protective effects of tea components are discussed below. O nly three studies have specifically investigated ovarian cancer [25-27], and these will be discussed separately.

\section{Antioxidant properties of green tea}

The antioxidant property of tea polyphenols is the most popular cancer preventive mechanism [23]. Antioxidants protect cells against the damaging effects of reactive oxygen species [23]. Catechins, especially EGCG , are highly effective scavengers of these oxidizing molecules, including singlet oxygen and various free radicals that are possibly involved in D N A damage and tumor promotion [28]. Animal studies have also shown that green tea catechins contribute to the total antioxidant defense system in the body by increasing total plasma antioxidant activity $[29,30]$.

\section{Influence on enzymes}

In addition to their individual antioxidant effect, animal and in vitro studies have found that green tea catechins increase the activity of several detoxifying and antioxidant enzymes that can metabolize carcinogens in the body into inactive products [30-33]. For example, EG CG is an effective inhibitor of enzymes crucial for cancer growth, such as urokinase [34] and telomerase [35]. H owever, tea polyphenols can interact with several enzymes or proteins implicated in cancer (e.g., ornithine decarboxylase, NADPH -cytochrome $\mathrm{P} 450$ reductase, protein kinase $C$, steroid 5- $\alpha$ reductase, tumor necrosis factor and epidermal growth factor expression, nitric oxide synthase and cyclooxygenase-2) [35].

Apoptosis \& cell-cycle progression arrest

Animal studies have demonstrated that both EGCG and theaflavins in tea can induce apoptosis [19] and cell-cycle arrest in many cancer cell lines [4]. It appears that green tea can selectively induce apoptosis in cancer cells and not normal cells [4]. A molecular mechanism proposed for these effects involves activation of the p53 protein and induction of the expression of Bax and p21, primary responser activation genes for $p 53$, all of which are involved in accelerating programmed cell death $[25,36]$. These findings imply that green tea has the potential for cancer prevention by inhibiting tumor development and in cancer progression by preventing tumor invasion, proliferation and angiogenesis [34].

Reactive oxygen species (ROS) and mitotic signal activation are considered to be major factors in tumor development [33]. RO S affect key transcription factors that are active mitotic signal transducers, leading to stimulation of cell proliferation, inflammation and tumor promotion. In terms of cancer chemoprevention, tea polyphenols can inhibit several of these transcription factors, such as activator protein-1 and nuclear factor- $\kappa \mathrm{B}$, thereby blocking mitotic signaling pathways [33].

\section{Synergistic action of green tea}

The mechanisms by which green tea may exert a protective effect on cancer are not yet fully understood. While EGCG is thought to be the most important component of green tea, it is likely that tea polyphenols may work synergistically so that green tea may have stronger anticancer effects than EGCG or any other component alone [24]. Evidence also exists that green tea components are more protective when taken with caffeine. Although the role of caffeine in carcinogenesis remains controversial, several animal studies have reported a protective effect of caffeine on UV-induced skin 
carcinogenesis [19-22]. O ne study observed strong inhibitory effects for caffeinated teas and caffeine but not decaffeinated tea [22]. Proposed mechanisms include the stimulatory effect of caffeine on UV-induced increases in the number of wild-type p53-positive cells, p21(WAF1/CIP1)-positive cells and apoptotic sunburn cells [19].

In vitro \& animal studies on green tea \& ovarian cancer

Three published studies specifically investigating ovarian cancer were identified for this article [25-27]. A cell culture study observed that EGCG suppressed cancer cell growth in three ovarian carcinoma cell lines [25]. Growth was suppressed through the induction of apoptosis and cell-cycle arrest. The proposed molecular mechanisms included regulation of the expression of particular genes and proteins (p53, Bax, p21, cyclin D 1 and $B c l-X_{L}$ ) related to cancer cell growth inhibition and apoptosis [25].

An animal study investigated the effects of theanine (a water-soluble amino acid found in green tea) on the M5076 ovarian sarcoma, together with the antitumor activity of doxorubicin (Adriamycin ${ }^{\circledR}$ ), an anthracycline antibiotic [26]. It concluded that theanine selectively increased the doxorubicin concentration in mice tumors by 2.7 -fold whereas it decreased the concentration in other tissues. This is an important finding because cardiac toxicity is a severe adverse side effect of doxorubicin [26]. Although the injection of doxorubicin alone did not inhibit tumor growth, the injection of doxorubicin and theanine significantly reduced tumor weight as compared with controls. The oral administration of green tea to mice produced similar effects, which demonstrated the modulating action of theanine or green tea on doxorubicin. A subsequent study by the same researchers found that theanine also enhanced the inhibition of hepatic metastasis induced by doxorubicin [27]. These results suggest that green tea can play an important role in the treatment of ovarian cancer.

Limitations of in vitro \& animal studies

Findings from in vitro and animal studies need to be supported by human studies that take into account the absorption and uptake of green tea compounds in vivo. $M$ any in vitro and animal studies used very high concentrations of catechins to demonstrate a protective effect $[4,23]$. However, green tea polyphenols undergo several processes after ingestion so that the high catechin concentrations do not reflect the actual levels found in the human body [4]. Furthermore, animal studies utilize a variety of preparation methods for green tea that can influence the content of green tea components such as catechins, leading to unstable levels [23]. It is thus difficult to evaluate the relationship between the amount of green tea ingestion and the biologic effect that can be applied to humans. There are also very few published reports specifically on ovarian cancer.

\section{Epidemiologic evidence}

The effect of green tea on ovarian cancer has not been investigated comprehensively; only one epidemiologic study has shown a preventive effect [5]. This case-control study was conducted in $\mathrm{H}$ angzhou, China. Cases included 254 hospital in-patients with ovarian cancer, whereas controls were 652 hospital visitors, out-patients or women from the community. D etailed information about frequency, type and duration of tea consumption was collected by personal interview using a validated questionnaire. The risk of epithelial ovarian cancer significantly declined with increasing consumption level and years of green tea drinking. The adjusted odds ratio $(O R)$ was 0.39 (95\% confidence interval [CI]: 0.27-0.57) for those drinking tea daily compared with never or seldom tea drinkers, while the OR was 0.23 (95\% Cl: 0.13-0.41) for women who drank tea for more than 30 years compared with nondrinkers. The risk of serous cell ovarian cancer appeared to have an even stronger inverse association with tea consumption. It should be remarked that over $90 \%$ of tea drinkers consumed green tea while the consumption of black and oolong tea was very low in $\mathrm{H}$ angzhou.

The follow-up study of the same patients reported that green tea affected the survival rate of ovarian cancer patients post diagnosis [6]. This prospective cohort study, which followed 244 ovarian cancer patients for a minimum of 3 years, found tea drinkers and non-tea drinkers had a different survival experience. $\mathrm{H}$ azard ratios declined with increasing frequency and quantity of green tea consumption. In particular, the adjusted hazard ratios were 0.55 (95\% $\mathrm{Cl}:$ 0.34-0.90) for tea drinkers compared with non-tea drinkers and 0.38 (95\% Cl: $0.15-0.97)$ for those consuming at least $2 \mathrm{~g}$ of dried tea leaves per batch as compared with less than $2 \mathrm{~g}$ per batch. All dose-response relationships were significant. 
In contrast, none of seven other studies (dating back to 1983) reported any significant association between tea consumption and ovarian cancer risk. An Australian case-control study found no association, but black tea was by far the most common type of tea consumed [37]. Five other case-control studies [38-42] and one cohort study [43] also showed little association between tea consumption and reduced risk of ovarian cancer. It should be noted, however, that these studies were all conducted either in the USA $[38,39,41,43]$ or Italy $[40,42]$, where tea drinking is much less prevalent than in China [37]. M oreover, the type of tea consumed was not specified, nor were the effects of different tea types examined. Table 1 summarizes and compares these epidemiologic studies.

There are several possible explanations for the null results. Firstly, the apparent differences between high and low consumptions in the USA- and Italian-based studies may not be large enough to demonstrate a statistically significant effect. Secondly, methodologic issues may have affected their findings. These include failure to control for potential confounding factors, problems quantifying tea intake and the lack of comprehensive assessment of tea consumption levels. For example, one study classified tea drinkers as 'rare' or 'weekly' drinkers only [41]. Unlike the $\mathrm{H}$ angzhou study [5], detailed information was not solicited on the consumption pattern, types of tea consumed, duration of tea drinking and tea preparation method. Thirdly, differences in habitual tea consumption between study populations may have contributed to the contrasting results. For example, tea consumption in Australia has declined by $22 \%$ in the 5 -year period from 1992-1993 to 1997-1998 [44], whereas the Chinese tea consumption pattern has remained relatively stable [5].

\section{Discussion}

The most definitive evidence of cancer prevention by green tea or tea components came from cell culture lines and animal studies. However,

\section{Table 1. Summary of epidemiologic studies on tea consumption and ovarian cancer.}

\begin{tabular}{|c|c|c|c|c|c|}
\hline Country & Study design & Sample size & Level of tea consumption & $\begin{array}{l}\text { Results: adjusted OR, } \\
\text { RR or HR ( } 95 \% \mathrm{CI})\end{array}$ & Refs \\
\hline China & $\begin{array}{l}\text { Case-control } \\
\text { (hospital based) }\end{array}$ & $\begin{array}{l}254 \text { cases, } \\
652 \text { controls }\end{array}$ & $\begin{array}{l}\geq 1 \text { cup/day }(350 \mathrm{ml} \text { ) versus } \\
\text { none } \\
>30 \text { years of consumption } \\
\text { versus never }\end{array}$ & $\begin{array}{l}\text { OR: } 0.39(0.27-0.57) \\
\text { OR: } 0.23(0.13-0.41)\end{array}$ & [5] \\
\hline China & Cohort & $\begin{array}{l}244 \text { ovarian } \\
\text { cancer patients }\end{array}$ & $\begin{array}{l}\geq 1 \text { cup/day ( } 350 \mathrm{ml} \text { ) versus } \\
\text { none }\end{array}$ & HR: $0.43(0.20-0.92)$ & [6]* \\
\hline Australia & $\begin{array}{l}\text { Case-control } \\
\text { (population } \\
\text { based) }\end{array}$ & $\begin{array}{l}696 \text { cases, } \\
786 \text { controls }\end{array}$ & $\geq 4$ cups/day versus none & OR: 1.10 (0.76-1.61) & [37] \\
\hline USA & $\begin{array}{l}\text { Case-control } \\
\text { (hospital based) }\end{array}$ & $\begin{array}{l}274 \text { cases, } \\
1034 \text { controls }\end{array}$ & $\geq 3$ cups/day versus none & $\begin{array}{l}\text { OR: } 0.84 \\
\text { (95\% CI not available) }\end{array}$ & [38] \\
\hline USA & $\begin{array}{l}\text { Case-control } \\
\text { (hospital based) }\end{array}$ & $\begin{array}{l}290 \text { cases, } \\
1056 \text { controls }\end{array}$ & $\geq 5$ cups/day versus none & $\begin{array}{l}\text { OR: } 0.70(0.3-1.6) \text { for } \\
\text { controls with cancer } \\
\text { OR: } 0.50(0.2-1.0) \text { for } \\
\text { cancer-free controls }\end{array}$ & [39] \\
\hline Italy & $\begin{array}{l}\text { Case-control } \\
\text { (hospital based) }\end{array}$ & $\begin{array}{l}742 \text { cases, } \\
6147 \text { controls }\end{array}$ & $\geq 1$ cup/month versus never & OR: 0.90 (0.75-1.08) & [40] \\
\hline USA & $\begin{array}{l}\text { Case-control } \\
\text { (population } \\
\text { based) }\end{array}$ & $\begin{array}{l}549 \text { cases, } \\
516 \text { controls }\end{array}$ & $\geq 1$ cup/week versus rarely & OR: 1.06 (0.83-1.36) & [41] \\
\hline Italy & $\begin{array}{l}\text { Case-control } \\
\text { (hospital based) }\end{array}$ & $\begin{array}{l}1031 \text { cases, } \\
2411 \text { controls }\end{array}$ & $\geq 1$ cup/day versus none & OR: 0.90 (0.75-1.08) & [42] \\
\hline USA & Cohort & $\begin{array}{l}35,369 \\
\text { postmenopausal } \\
\text { women }\end{array}$ & $\geq 2$ cups/day versus none & RR: 0.98 (0.50- 1.90) & [43] \\
\hline
\end{tabular}

*Study on tea consumption and ovarian cancer survival.

HR: Hazard ratio; OR: Odds ratio; RR: Relative risk. 
the effects observed in these model systems are not always reproducible in humans. While epidemiologic evidence for several cancers is growing, only one published epidemiologic study has shown a preventive effect specifically on ovarian cancer [5].

There is emerging evidence for the role of green tea in ovarian cancer prevention but more evidence is required, especially from human studies. D efining the biologic mechanisms of various tea components is an important area of research. Evidence is also lacking on the dosage required for effect, efficacy of absorption and attainable blood levels, as well as the chemopreventive effects of different types of tea. Black tea is commonly consumed in Western countries [17], yet the majority of in vitro and animal studies have focussed on green tea. The chemistry and chemopreventive properties of black tea are still not understood. Current evidence suggests that green tea may offer stronger protection than other types of tea due to its higher catechin content [18]. On the other hand, it is possible that green tea drinking may simply serve as a marker of a healthy lifestyle protective against cancer. In addition, green tea may have different chemopreventive effects on different subtypes of ovarian cancer, in view of their varying etiologies [2]. This issue has not been fully explored in the literature.

M ore observational studies should be conducted in a variety of populations who consume different types and amounts of tea, before conducting large scale clinical trials. N evertheless, green tea is a safe and cheap beverage. The consumption of green tea should be encouraged because of its potential as a practical method of cancer prevention and complementary cancer treatment.

\section{Future perspectives}

It is envisaged that over the next decade further support will emerge from in vitro, animal and epidemiologic studies concerning the effects of green tea on ovarian cancer prevention and treatment. Provided that findings are favorable, large-scale randomized controlled trials will then follow to ensure its efficacy. O nce additional evidence for the preventive effect of green tea on other cancers and lifestyle diseases becomes available, dosage recommendations for green tea will be made and its consumption will increase substantially in Western societies.

\section{Executive summary}

\section{Introduction}

- Ovarian cancer is the leading cause of death from gynecologic cancer. The incidence of ovarian cancer varies considerably across countries.

- Green tea is an unfermented form of tea rich in catechins, a category of polyphenols that have chemopreventive properties.

- Green tea has shown promise in the prevention of several cancers, including ovarian cancer.

\section{In vitro \& animal studies}

- In vitro cell cultures and animal studies have provided strong evidence of green tea or tea components in cancer prevention. Potential mechanisms include its antioxidant properties, influence on enzymes, induction of apoptosis and cell-cycle arrest.

- Two studies found that green tea or theanine could enhance the effectiveness of ovarian cancer treatment.

\section{Epidemiologic evidence}

- Human case-control and cohort studies have generated inconsistent results.

- Recent research conducted in China reported reduced risk of ovarian cancer and increased survival post diagnosis with green tea consumption.

\section{Future perspectives}

- Green tea is a safe and cheap beverage. Its consumption should be encouraged.

- Although green tea plays a role in ovarian cancer prevention, its effects on different subtypes of ovarian cancer need to be investigated.

- Further studies in a variety of populations who consume different types and amounts of tea are required prior to conducting large-scale clinical trials.

- Once additional evidence for the preventive effect of green tea becomes available, dosage recommendations for green tea will be made and its consumption will increase substantially in Western societies. 
Bibliography

Papers of special note have been highlighted as either of interest $(\bullet)$ or of considerableinterest $(\cdot \bullet)$ to readers.

1. H olschneider $\mathrm{CH}$, Berek JS: O varian cancer: epidemiology, biology and prognostic factors. Semin. Surg. 0 ncol. 19(1), 3-10 (2000).

2. Stewart BW, Kleihues $P(E d s)$ : World Cancer Report. IARC Press, Lyon, France (2003).

3. Zhang $M$, Lee AH, Binns CW: Reproductive and dietary risk factors for epithelial ovarian cancer in China. Gynecol. Oncol. 92(1), 320-326 (2004).

4. Chung FL, Schwartz J, H erzog CR, Yang YM : Tea and cancer prevention: studies in animals and humans. J. N utr. 133(10), S3268-S3274 (2003).

5. Zhang M, Binns CW, Lee AH: Tea consumption and ovarian cancer risk: a case control study in China. Cancer Epidemiol. Biomarkers Prev. 11(8), 713-718 (2002).

- O nly case-control study that demonstrates a significant inverse association between green tea consumption and ovarian cancer risk.

6. Zhang M, LeeAH, Binns CW, XieX: Green tea consumption enhances survival of epithelial ovarian cancer. Int. J. Cancer. 112(3), 465-469 (2004).

- Cohort study demonstrating enhanced survival of ovarian cancer patients with increasing frequency and quantity of green tea consumption.

7. Setiawan VW, Zhang ZF, Yu G P: Protective effect of green tea on the risks of chronic gastritis and stomach cancer. Int. J. Cancer. 92(4), 600-604 (2001).

8. Sun CL, Yuan JM , Lee M J et al.: U rinary tea polyphenols in relation to gastric and esophageal cancers: a prospective study of men in Shanghai, China. Carcinogenesis 23(9), 1497-1503 (2002).

9. Sasazuki $S$, Inoue $M$, , H anaoka T, Yamamoto S, Sobue T, Tsugane S: G reen tea consumption and subsequent risk of gastric cancer subsite: the JPH C study. Cancer Causes Control 15(5), 483-491 (2004).

10. Su LJ, Arab L: Tea consumption and the reduced risk of colon cancer - results from a national prospective cohort study. Pub. H ealth N utr. 5(3), 419-425 (2002).

11. H akim IA, H arris RB, Weisgerber U M : Tea intake and squamous cell carcinoma of the skin: influence of type of tea beverages. Cancer Epidemiol. Biomarkers Prev. 9(7), 727-731 (2000).

12. Jian L, Xie LP, LeeAH, Binns CW: Protective effect of green tea against prostate cancer: a case control study in southeast
China. Int. J. Cancer. 108(1), 130-135 (2004).

13. Wu AH, Yu M C, Tseng CC, $H$ ankin J, Pike M C: Green tea and risk of breast cancer in Asian Americans. Int. J. Cancer. 106(4), 574-579 (2003).

14. Nakachi $K$, Suemasu $K$, Suga $K$, Takeo $T$, Imai $\mathrm{K}, \mathrm{H}$ igashi $Y$ : Influence of drinking green tea on breast cancer malignancy among Japanese patients. J pn. J. Cancer Res. 89(3), 254-261 (1998).

15. Inoue M, Tajima K, M izutani $\mathrm{M}$ et al.: Regular consumption of green tea and the risk of breast cancer recurrence: follow-up study from the H ospital-based Epidemiologic Research Program at Aichi Cancer Center (H ERPACC), Japan. Cancer Lett. 167(2), 175-182 (2001).

16. Nagano J, Kono S, Preston D L, M abuchi K: A prospective study of green tea consumption and cancer incidence, $\mathrm{H}$ iroshima and $\mathrm{N}$ agasaki (Japan). Cancer Causes Control 12(6), 501-508 (2001).

17. Mukhtar $\mathrm{H}, \mathrm{Ahmad} \mathrm{N}$ : Tea polyphenols: prevention of cancer and optimizing health. Am. J. Clin. Nutr. 71(6), S1698-S1702 (2000).

18. Graham H N : Green tea composition, consumption, and polyphenol chemistry. Prev. M ed. 21(3), 334-350 (1992).

19. Lu YP, Lou YR, Li XH et al.: Stimulatory effect of oral administration of green tea or caffeine on ultraviolet p53, p21 (WAF1/CIP1), and apoptotic sunburn cells in SKH -1 mice. Cancer Res. 60(17), 4785-4791 (2000).

20. Lu YP, Lou YR, XieJG et al.: Topical applications of caffeine or (-)epigallocatechin gallate (EGCG) inhibit carcinogenesis and selectively increase apoptosis in UVB-induced skin tumors in mice. Proc. N atl Acad. Sci. U SA 99(19), 12455-12460 (2002).

21. Lou YR, Lu YP, Xie JG, H uang MT, Conney AH : Effects of oral administration of tea, decaffeinated tea and caffeine on the formation and growth of tumors in highrisk SKH -1 mice previously treated with ultraviolet B light. N utr. Cancer. 33(2), 146-153 (1999).

22. H uang $M T, X i e J G$, Wang $Z Y$ et al.: Effects of tea, decaffeinated tea, and caffeine on U V B light-induced complete carcinogenesis in SKH -1 mice: demonstration of caffeineas a biologically important constituent of tea. Cancer Res. 57(13), 2623-2629 (1997).

23. Crespy $\mathrm{V}, \mathrm{W}$ illiamson $\mathrm{G}: \mathrm{A}$ review of the health effects of green tea catechins in in vivo animal models. J. N utr. 134(12), S3431-S3440 (2004).
24. Suganuma M, O kabe S, Sueoka N et al.: $G$ reen tea and cancer chemoprevention. Mutation Res. 428(1-2), 339-344 (1999).

25. Huh SW, Bae SM, Kim YW et al.: Anticancer effects of (-)-epigallocatechin-3gallate on ovarian carcinoma cell lines. Gynecol. Oncol. 94(3), 760-768 (2004).

- Cell culture study examining the effects of epigallocathechin-3 gallate (EG C G) specifically on ovarian carcinoma cell lines. Important findings include that EG C G suppresses cancer cell growth by inducing apoptosis and cell-cycle arrest.

26. Sugiyama T, Sadzuka Y: Enhancing effects of green tea components on the antitumor activity of adriamycin against M 5076 ovarian sarcoma. Cancer Lett. 133(1), 19-26 (1998).

- Animal study reporting the enhancing effects of theanine (found in green tea) or green tea on ovarian cancer treatment Adriamycin ${ }^{\circledR}$.

27. Sugiyama T, Sadzuka Y: Combination of theanine with doxorubicin inhibits hepatic metastasis of M 5076 ovarian sarcoma. Clin. Cancer Res. 5(2), 413-416 (1999).

28. Anderson RF, Fisher $L J$, $H$ ara $Y$ et al.: Green tea catechins partially protect $D N A$ from (.) $\mathrm{OH}$ radical-induced strand breaks and base damage through fast chemical repair of D N A radicals. Carcinogenesis 22(8), 1189-1193 (2001).

29. Yokozawa T, N akagawa T, Kitani K: Antioxidative activity of green tea polyphenol in cholesterol-fed rats. J. Agric. Food Chem. 50(12), 3549-3552 (2002).

30. Skrzydlewska E, O strowska J, Farbiszewski R, M ichalak K: Protective effect of green tea against lipid peroxidation in the rat liver, blood serum and the brain. Phytomedicine 9(3), 232-238 (2002).

31. D onovan JL, C respy V, M anach C et al.: Catechin is metabolized by both the small intestine and liver of rats. J. N utr. 131(6), 1753-1757 (2001).

32. Lu H, M eng X, Li C et al.: Glucuronides of tea catechins: enzymology of biosynthesis and biological activities. D rug M etab. D ispos. 31(4), 452-461 (2003).

33. Lin JK: C ancer chemoprevention by tea polyphenols through modulating signal transduction pathways. Arch. Pharm. Res 25(5), 561-571 (2002).

34. Jung YD, Ellis LM : Inhibition of tumour invasion and angiogenesis by epigallocatechin gallate (EGCG), a major component of green tea. Int. J. Exp. Pathol. 82(6), 309-316 (2001). 
35. N aasani I, O h-H ashi F, O h-H ara T et al.: Blocking telomerase by dietary polyphenols is a major mechanism for limiting the growth of human cancer cells in vitro and in vivo. Cancer Res.63(4), 824-830 (2003).

36. H astak K, Agarwal M K, M ukhtar H, Agarwal M L: Ablation of either p21 or Bax prevents p53-dependent apoptosis induced by green tea polyphenol epigallocatechin-3gallate. FASEB J. 19(7), 789-791 (2005).

37. Jordan SJ, Purdie D M, Green AC, Webb PM : C offee, tea and caffeine and risk of epithelial ovarian cancer. Cancer Causes Control 15(4), 359-365 (2004).

38. Byers T, M arshall J, Graham S, M ettlin C, Swanson M : A case-control study of dietary and nondietary factors in ovarian cancer. J. N atl Cancer Inst. 71(4), 681-686 (1983).

39. M iller $D R$, Rosenberg $L, K$ aufman $D W$ et al.: Epithelial ovarian cancer and coffee drinking. Int. J. Epidemiol. 16(1), 13-17 (1987).
40. La Vecchia C, N egre E, Franceschi S, D 'Avanzo B, Boyle P: Tea consumption and cancer risk. N utr. Cancer. 17(1), 27-31 (1992).

41. Kuper $H$, Titus-Ernstoff $L, H$ arlow BL, Cramer DW: Population based study of coffee, alcohol and tobacco use and risk of ovarian cancer. Int. J. Cancer. 88(2), 313-318 (2000).

42. Tavani $A, G$ allus $S, D$ al $M$ aso $L$ et al.: Coffee and alcohol intake and risk of ovarian cancer: an Italian case-control study. N utr. Cancer. 39(1), 29-34 (2001).

43. Zheng W, D oyle TJ, Kushi LH, Sellers TA, $H$ ong $C P$, Folsom AR: Tea consumption and cancer incidence in a prospective cohort study of postmenopausal women. Am. J. Epidemiol. 144(2), 175-182 (1996).

44. Australian Bureau of Statistics. Apparent Consumption of Foodstuffs, Australia. Cat. N o. 4315, Canberra, ABS (2002).
Affiliations

- AndyH Le

Curtin University of Technology, School of Public H ealth, GPO Box U 1987, Perth, WA 6845 , Australia Tel.: +61 892664 180; Fax: +61 892662 958; Andy.Le@curtin.edu.au

- MichelleL Fraser Curtin U niversity of Technology, School of Public H ealth, Perth, WA, Australia

- Colin W Binns Curtin U niversity of Technology, School of Public H ealth, Perth, WA, Australia 